\title{
Correction to: Recent developments in photoacoustic imaging and sensing for nondestructive testing and evaluation
}

\author{
Sung-Liang Chen ${ }^{1,2,3^{*}}$ and Chao Tian ${ }^{4^{*}}$
}

\section{Correction to: Vis Comput Ind Biomed Art 4, 6 (2021) \\ https://doi.org/10.1186/s42492-021-00073-1}

Following publication of the original article [1], the authors identified an error in the article title. The first word 'Review' is added mistakenly by the typesetter.

The incorrect article title is: Review recent developments in photoacoustic imaging and sensing for nondestructive testing and evaluation.

The correct article title is: Recent developments in photoacoustic imaging and sensing for nondestructive testing and evaluation.

The article title has been updated in this correction and the original article [1] has been corrected.

\section{Author details}

${ }^{1}$ University of Michigan-Shanghai Jiao Tong University Joint Institute, Shanghai Jiao Tong University, Shanghai 200240, China. ${ }^{2}$ Engineering Research Center of Digital Medicine and Clinical Translation, Ministry of Education, Shanghai 200030, China. ${ }^{3}$ State Key Laboratory of Advanced Optical Communication Systems and Networks, Shanghai Jiao Tong University, Shanghai 200240, China. ${ }^{4}$ Department of Precision Machinery and Precision Instrumentation, University of Science and Technology of China, Hefei 230026, Anhui, China.

Published online: 29 April 2021

\section{Reference}

1. Chen SL, Tian C (2021) Recent developments in photoacoustic imaging and sensing for nondestructive testing and evaluation. Vis Comput Ind Biomed Art 4:6. https://doi.org/10.1186/s42492-021-00073-1

\footnotetext{
The original article can be found online at https://doi.org/10.1186/s42492021-00073-1.

* Correspondence: sungliang.chen@sjtu.edu.cn; ctian@ustc.edu.cn

'University of Michigan-Shanghai Jiao Tong University Joint Institute,

Shanghai Jiao Tong University, Shanghai 200240, China

${ }^{4}$ Department of Precision Machinery and Precision Instrumentation,

University of Science and Technology of China, Hefei 230026, Anhui, China

Full list of author information is available at the end of the article
}

望 Springer Open

(c) The Author(s). 2021 Open Access This article is licensed under a Creative Commons Attribution 4.0 International License, which permits use, sharing, adaptation, distribution and reproduction in any medium or format, as long as you give appropriate credit to the original author(s) and the source, provide a link to the Creative Commons licence, and indicate if changes were made. The images or other third party material in this article are included in the article's Creative Commons licence, unless indicated otherwise in a credit line to the material. If material is not included in the article's Creative Commons licence and your intended use is not permitted by statutory regulation or exceeds the permitted use, you will need to obtain permission directly from the copyright holder. To view a copy of this licence, visit http://creativecommons.org/licenses/by/4.0/. 